\title{
NK cell therapy for hematologic malignancies
}

\author{
Rohtesh S. Mehta ${ }^{1} \cdot$ Brion Randolph ${ }^{1} \cdot$ May Daher $^{1} \cdot$ Katayoun Rezvani $^{1}$
}

Received: 9 January 2018 / Accepted: 22 January 2018 / Published online: 27 January 2018

(c) The Japanese Society of Hematology 2018

\begin{abstract}
Natural killer (NK) cells are part of the innate immune system and represent the first line of defense against infections and tumors. In contrast to T cells, NK cells do not require prior antigen sensitization to induce cytotoxicity and do not cause graft-versus-host disease. These, along with other advantages, make NK cells an attractive candidate for adoptive cellular therapy. Herein, we describe the mechanisms of NK cell cytotoxicity, which is governed by an intricate balance between various activating and inhibitory receptors, including the killer cell immunoglobulin-like receptors (KIRs). We illustrate the advantages of NK alloreactivity as demonstrated in various types of hematopoietic stem cell transplants (HSCT), such as haploidentical, human leukocyte antigen-matched related or unrelated donor and umbilical cord blood transplant. We elaborate on different models used to predict NK cell alloreactivity in these studies, which are either based on the absence of the ligands for inhibitory KIRs, presence of activating NK cell receptors and KIR genes content in donors, or a combination of these. We will review clinical studies demonstrating anti-tumor efficacy of NK cells used either as a stand-alone immunotherapy or as an adjunct to HSCT and novel genetic engineering strategies to improve the anti-tumor activity of NK cells.
\end{abstract}

Keywords NK cells · Natural killer cells · Adoptive immunotherapy · Immunotherapy $\cdot$ Haploidentical $\cdot$ Cord blood · Hematopoietic stem cell transplant $\cdot$ Stem cell transplant $\cdot$ KIR $\cdot$ KIR mismatch $\cdot$ HLA mismatch

\section{Introduction}

Natural killer (NK) cells are very potent effector lymphocytes that can induce cytotoxicity against a vast array of tumors without the need for antigen specificity. They are the first subset of lymphocytes to reconstitute after hematopoietic stem cell transplant (HSCT) [1], and likely play an important role in offering protection against relapse in the early months after transplant. In contrast to T cells, NK cells do not cause graft-versus-host disease (GVHD) in the allogeneic setting; indeed, a number of preclinical studies suggest that they may even protect against GVHD by targeting the recipient's dendritic cells [2-5]. Owing to these unique properties, multiple studies are exploring the role of NK cells in the context of HSCT or as adoptive cellular therapy (ACT). There are multiple potential source of NK cells for adoptive

Rohtesh S. Mehta

Rmehta1@mdanderson.org

1 Department of Stem Cell Transplant and Cellular Therapy, University of Texas M. D. Anderson Cancer Center, Unit 0423, 1515 Holcombe Blvd., Houston, TX 77030, USA cellular therapy, including bone marrow (BM), peripheral blood (PB), readily available cryopreserved umbilical cord blood (CB), various cells lines, such as the NK-92, KHYG-1 $[6,7]$, or human embryonic stem cells (hESCs) [8] and induced pluripotent stem cells (iPSCs) $[8,9]$.

\section{Mechanism of action of NK cells}

NK cells are $\mathrm{CD}^{-}$and $\mathrm{CD} 56^{+} / \mathrm{CD} 16^{+}$large granular lymphocytes that can be classified into two broad subsets-the naïve $\mathrm{CD} 56^{\text {bright }} \mathrm{CD} 16^{\mathrm{dim}}$ cells and the mature CD56 ${ }^{\mathrm{dim}} \mathrm{CD} 16^{\text {bright }}$ cells which are highly cytotoxic [10]. Contrary to T cells, NK cells do not require prior antigen sensitization or antigen presentation by the major histocompatibility complex (MHC) class I molecules to recognize their targets [11-13]. Their cytotoxicity rather depends upon complex interactions between their various germline-encoded activating and inhibitory receptors and ligands on the surface of target cells. Among these, the NK cell killer immunoglobulin (Ig)-like receptors (KIRs) are most extensively studied. The inhibitory NK cell receptors include various 
KIRs (KIR2DL1, KIR2DL2/L3, KIR2DL4, KIR2DL5A, KIR2DL5B, KIR3DL1, KIR3DL2 and KIR3DL3) [14] and a C-type lectin receptor-NKG2A. Known ligands for some of the inhibitory KIRs are HLA-C1-related alleles ( $\mathrm{Cw} 2$, Cw5, and Cw6) for KIR2DL2 and KIR2DL3; HLA-C2-related alleles (Cwl, Cw3, Cw7, and Cw8, C*02/04/05/06/1 2:42/15/16:02/17) for KIR2DL1 and HLA-Bw4 alleles for KIR3DL1 [15-18]. Various activating receptors on NK cells include the natural cytotoxicity receptors (NCRs-NKp30, NKp44 and NKp46), C-type lectin receptors (NKG2C and NKG2D), the DNAX accessory molecule-1 (DNAM-1 or CD226) and the activating KIRs (KIR2DS1, KIR2DS2, KIR2DS3, KIR2DS4, KIR2DS5) [14, 19-27]. In contrast to the inhibitory KIRs, the ligands for activating KIRs are less well understood, except KIR2DS1 and KIR2DS5, both of which recognize HLA-C2-related alleles, albeit with a lower affinity than their inhibitory counterparts [28-31]. KIR2DS2 was initially reported to recognize HLA-A*11the functional significance of which remains unknown [32], and more recently shown to interact with an as yet unknown $\beta_{2}$-microglobulin-independent ligand on cancer cells [33]. Other NK cell-activating receptors such as NKG2D recognize stress-induced molecules including the MHC class I-related genes (MICA and MICB) and UL16-binding proteins (ULBP) [19, 20, 34].

The interaction of the inhibitory receptors with their ligands (self MCH class I molecules) inhibits NK cell activity. According to the "missing self" hypothesis, if this inhibitory signal is lost or dampened [11,35,36], as is the case on tumor cells or virally infected cells, NK cells become predestined to kill $[37,38]$. Although "missing self" is critical, it is not sufficient to trigger NK cytotoxicity, which also requires stimulatory signals generated by the ligation of activating receptors [39-41]. Further, the activity of NK cells is also uniquely augmented by the expression of CD16, which is a transmembrane receptor that binds to the $\mathrm{Fc}$ portion of IgG on target cells leading to antibody-dependent cellular cytotoxicity (ADCC) $[42,43]$.

\section{Autologous NK cell immunotherapy}

Many early clinical trials initially explored the possibility of expanding and enhancing the anti-tumor activity of the native lymphocytes of patients in vivo simply by giving patients high-dose interleukin-2 (IL-2) [44-50]. The use of high-dose IL-2 led to enormous expansion of NK cells in vivo-up to $2500 \%$ or more over baseline [46-50] and enhanced in vitro lytic activity against NK-resistant cell lines [47-49]. The foundation of ACT was laid by the National Cancer Institute group led by Rosenburg et al. in the early 1980s using autologous "lymphokine-activated killer" (LAK) cells generated ex vivo by incubating human PB lymphocytes with IL-2 [51, 52]. The clinical responses to LAK cells infused along with high-dose IL-2 were less than optimal and produced unacceptable IL-2 related toxicities. Nonetheless, responses in some of the end-stage metastatic cancer patients, with some complete remissions (CR), were exciting and generated further interest in the field [51-54]. Thereafter, many studies utilized ex vivo activated/expanded autologous NK cells along with intravenous or subcutaneous low-dose IL-2 [46, 55-57]. Although low-dose IL-2 was better tolerated, responses remained suboptimal, likely due to IL-2-induced expansion of regulatory T cells $\left(\mathrm{T}_{\text {regs }}\right)$ which inhibit NK cell proliferation and function [58], and/ or due to the inhibition of autologous NK cells by the selfHLA molecules on the tumor cells. Due to these limitations, the use of allogeneic NK cells was the next logical step for investigators to explore.

\section{Allogeneic NK cell immunotherapy in the setting of HSCT}

Allogeneic HSCT creates a unique condition for NK cell alloreactivity by virtue of the "missing-self" phenomenon. As the KIR genes (chromosome 19q13.4) and the HLA genes (chromosome 6p21) segregate independently, a donor-recipient pair can be HLA-matched and KIR-mismatched simultaneously [59]. In fact, only about $25 \%$ of the HLA-matched sibling donor/recipient pairs are KIR identical, while the probability of an HLA-matched unrelated donor (MUD)/recipient pair to be KIR identical is virtually zero [60]. A KIR ligand mismatch in HSCT can be predicted using an online calculator (https://www.ebi.ac.uk/ipd/kir/ ligand.html) by entering the HLA types of the donor and the recipient.

\section{Donor-recipient KIR ligand mismatch in the setting of haploidentical HSCT}

The potent anti-tumor efficacy of allogeneic NK cells was first clinically demonstrated in the context of HSCT by Ruggeri et al. [2] in a study of patients with acute myeloid leukemia (AML) or acute lymphoblastic leukemia (ALL) who underwent T cell-depleted PB haploidentical transplant. As compared to the patients who received KIR ligand-matched HSCT, patients undergoing a KIR ligand-mismatched HSCT had a significantly lower risk of relapse ( $75 \mathrm{vs.} 0 \%$ at 5 years, respectively) and improved overall survival (OS; 5 vs. 60\%, respectively). For unclear reasons, the beneficial effect of KIR ligand mismatch was noticeable only in AML patients. Similar findings were observed in a subsequent study including a larger cohort of AML patients [61].

Although these results are fascinating, T cell-depleted haploidentical HSCT is rarely performed nowadays due to 
higher risk of relapse and non-relapse mortality as compared with an unmanipulated (T-cell replete) HSCT [62-64]. Moreover, the introduction of novel GVHD prophylaxis regimens, such as the use of post-transplant cyclophosphamide (PT-Cy) has led to a universal increase in the numbers of unmanipulated haploidentical HSCT [65-67]. The impact of PT-Cy on NK cell alloreactivity in patients undergoing myeloablative unmanipulated haploidentical HSCT was recently explored by Russo et al. in 99 patients with hematological malignancies (60\% with AML) [68]. Within the first few days of HSCT, mature graft-derived NK cells proliferated to a greater extent than $\mathrm{T}$ cells, but these proliferating cells, including the potentially alloreactive single$\mathrm{KIR}^{+} \mathrm{NK}$ cells, were rapidly eliminated by cyclophosphamide (administered on days +3 and +4 post HSCT). By day 15 , a second wave of NK cells emerged with an immature CD56 ${ }^{\text {bright }} \mathrm{NKG}_{2} \mathrm{~A}^{+} \mathrm{CD} 62^{+} \mathrm{KIR}^{-}$phenotype. Although NK cells remained the dominant lymphocytes for the first 3 months post HSCT, full reconstitution of a mature population took about 6-12 months. Consequently, patients with predicted NK alloreactivity $(n=41)$ had similar outcomes [GVHD, relapse and progression free survival (PFS)] as those without NK alloreactivity $(n=58)$ [68].

In contrast, two other studies in unmanipulated haploidentical HSCT and PT-Cy showed conflicting effects of NK alloreactivity on outcomes. The larger of these included 144 patients with various hematological (65\% lymphoid) malignancies who received primarily non-myeloablative conditioning (65\%). In this study, the benefit of KIR ligand mismatch (lower relapse risk and improved PFS) was restricted to patients who had active disease at the time of HSCT, but not in those who were in CR [69]. Yet another study $(n=34)$ showed significantly higher risk of acute GVHD (13/17 vs. $6 / 17, p=0.001)$ and lower relapse ( $2 / 17$ vs. $7 / 17, p=0.05)$ in patients with KIR ligand mismatch than those with no mismatch [70]. Variability in the conditioning regimens, patient populations and methods to assess NK cell alloreactivity in these studies could account for the differences in outcomes. Nevertheless, these studies suggest that the donor-recipient KIR ligand mismatch should not be used a prime determinant while selecting a donor for patients undergoing T-cell replete haploidentical HSCT with PT-Cy.

Can the potentially detrimental effect of PT-Cy on NK cell alloreactivity be compensated for by supplemental infusions of NK cells in the peri-transplant setting? This question was assessed in a study by Ciurea et al. [71] who administered multiple infusions of ex vivo expanded NK cells to patients with myeloid malignancies $(n=13)$ undergoing unmanipulated haploidentical HSCT. Patients received reduced intensity conditioning (RIC) with fludarabine and melphalan, followed by PT-Cy on days +3 and +4 . NK cells were infused on days $-2,+7$ and +28 . Five of the 13 patients were KIR ligand mismatched with their donors.
As compared to historical controls $(n=45)$ treated with the same conditioning regimen but without the supplemental NK cell infusions, patients who received NK cells had higher frequencies of TNF- $\alpha$ and IFN- $\gamma$ secreting NK cells at day 28 and had a higher proportion of mature/potentially alloreactive single-KIR ${ }^{+}$NK cells expressing CD16 and NKG2C. Yet, the authors did not observe any differences in the incidence of acute or chronic GVHD, relapse or PFS; NK cells, however, appeared to be protective against cytomegalovirus reactivation ( $31 \%$ in the NK group vs. $70 \%$-in the non-NK controls, $p=0.01$ ).

\section{Donor-recipient KIR ligand mismatch in HLA-matched related or unrelated donor HSCT}

The impact of KIR ligand mismatch on HSCT outcomes has also been studied extensively in the setting of HLA-matched related [72-76] or unrelated [73, 76-83] donor transplants using T-cell replete $[73,75,76,78-80,82]$ or T-cell deplete $[72,74,77,79-81]$ grafts with conflicting results. A common factor that surfaces from these heterogeneous studies is that a T-lymphopenic environment, created using in vivo or ex vivo T-cell depletion, is critical to harness the benefits of NK cells. This echoes findings from studies showing that $T$ cells can dominate and dampen NK cell alloreactivity [84, 85].

The conflicting results can also be explained by differences in the definitions of KIR ligand mismatch among the studies, significant polymorphisms in the KIR genes and the stochastic surface expression of specific KIRs on individual NK cells. For instance, not all KIR ligand mismatches have equal "strength." The inhibitory potential of KIR2DL1-HLA-C2 interaction is much stronger than that of KIR2DL2/3-HLA-C1 [16, 86, 87]. Moreover, even within a specific KIR-HLA ligand combination, the strengths of their interactions can vary among individuals. In case of HLABw4-KIR3DL1, the interaction can be strong (isoleucine; $\mathrm{Bw} 4-80 \mathrm{I}$ ) or weak (threonine; Bw4-80T), depending upon the HLA-Bw4 amino acid residue at position 80 and whether the surface expression of KIR3DL1 is high (3DL $1^{\text {high }}$ ) or low $\left(3 \mathrm{DL} 1^{\text {low }}\right)[86,88,89]$. KIR3DL $1^{\text {high }}$ has a higher affinity for, and hence induces a greater inhibitory signal, with Bw4-80I than Bw4-80T, while the opposite is true for KIR3DL1 $1^{\text {low }}$, which has a higher affinity for Bw4-80T [86, 90]. The clinical implications of these findings were illustrated by Boudreau et al. [90] in a study of 1328 patients with AML who underwent 9/10- or 10/10-MUD HSCT. The authors categorized patients into having either weak/noninhibitory or strong inhibitory KIR3DL1/HLA-Bw4 interactions. Patients with weak/no inhibition of KIR3DL1 had a significantly lower risk of relapse (HR, $0.72 ; p=0.004)$ and improved PFS (64 vs. 39\%, $p=0.05$ ) compared to those with strong inhibitory combinations. This protective effect 
was independent of and additive to the presence of donor activating KIR2DS1 [90].

\section{Impact of activating NK-cell receptors and KIR haplotypes on HSCT outcomes}

In contrast to the KIR ligand mismatch model described above, which primarily focuses on the degree of mismatch between the inhibitory KIRs and their ligands, a different perspective of NK alloreactivity focuses on their activating KIR profile. Based on the composition of activating and inhibitory KIRs, the KIR repertoire can be classified broadly into two KIR haplotypes [14]. Haplotype A is characterized by a predominance of inhibitory genes-specifically, 5 inhibitory KIR genes and a single activating gene (KIR2DS4) [14]. Conversely, haplotype B is characterized by a predominance of activating genes (KIR2DS1, KIR2DS2, KIR2DS3, KIR2DS5, KIR3DS1) and only one inhibitory gene (KIR2DL5) [14]. Furthermore, each KIR haplotype is a combination of a centromeric and a telomeric KIR gene motif [91]. Genes encoding the inhibitory receptors for the HLA-C1 and $\mathrm{C} 2$ epitopes are located in the centromeric region, while the telomeric region contains genes encoding the activating receptor for HLA-C2 (KIR2DS1) and the inhibitory receptors for the HLA-Bw4 and HLAA3/11 epitopes [91]. This specific organization and content of KIR genes carry important clinical significance.

The impact of KIR haplotype on HSCT outcomes was evaluated by Cooley et al. in a study of 448 AML patients who received T-cell replete unrelated donor transplant [92]. There was no impact of recipient KIR haplotype on survival; however, HSCT from a KIR B/x donor as compared with KIR A/A donor was associated with a significantly improved PFS (28 vs. $17 \%$ at 3 years, $p=0.003$ ) and OS (31 vs. $20 \%$ at 3 years, $p=0.007$ ). This effect was noted in patients who received KIR ligand-matched (HLA-matched or -mismatched) HSCT, but not in HLA-mismatched/KIR ligand-mismatched HSCT. In an attempt to explore the underlying mechanism for this protective effect, the authors noted that two donor KIR genes-KIR2DL2 and KIR2DS2, which are in strong linkage disequilibrium with each other, had independent effects on survival, but definitive analyses were restricted due to limited power. This was investigated in their subsequent study with a larger cohort of patients with AML $(n=1086)$ or ALL $(n=323)$ who received myeloablative, T-cell replete unrelated donor HSCT. Similar to the prior study, donor KIR B/x haplotype was associated with superior outcomes; however, the advantage was most pronounced if the KIR B genes were homozygous and located in the centromeric region $(\mathrm{Cen}-\mathrm{B} / \mathrm{B})$. This group $(\mathrm{Cen}-\mathrm{B} / \mathrm{B})$ had a significantly lower probability of relapse than those with either Cen-A/A or Cen-A/B donor [93]. Moreover, the relapse protection offered by the donor KIR B genes appeared to be more specific for $\mathrm{C} 1 / \mathrm{x}$ recipients than $\mathrm{C} 2 /$ C2 recipients [94].

An independent role for specific activating genes on outcomes, particularly donor KIR2DS1 and KIR3DS1, has also been reported [95-97]. In a study of 1277 patients with AML who had received a MUD HSCT, Venstrom et al. showed that receipt of an allograft from a KIR2DS1-positive donor was associated with a $24 \%$ lower risk of relapse than from a KIR2DS1-negative donor [97]. However, this protection was dependent upon both donor and recipient HLA-C. The benefit was noted only for $\mathrm{C} 1 / \mathrm{x}$ donors and recipients but not for HLA-C2/C2 donors or recipients. Also, donor KIR3DS1 was associated with $17 \%$ lower risk of mortality with no impact on relapse [97].

In contrast, KIR2DS4, which is the only activating gene within the KIR A haplotype, appears to impart detrimental outcomes after HSCT, especially if it is fully expressed on the cell membrane. KIR2DS4 has two allelic variants-full-length (KIR2DS4 full_-2DS4*00101) or deleted (KIR2DS $4{ }^{\text {del }}$-including 2DS4*003, S4*004 and S4*006) [98-100]. The latter yields a truncated KIR2DS4 protein, which is not bound to the cell membrane but is rather secreted in a soluble form [99]. The impact of donor KIR2DS4 on HSCT outcomes was assessed in 111 Croatian patients with a variety of hematological malignancies who underwent T-cell replete HLA-matched related or unrelated donor HSCT. Among related donor HSCT recipients, patients whose donors had 1-2 KIR2DS4 ${ }^{\text {full }}$ alleles had a significantly lower OS as compared to patients whose donors had a KIR2DS4 ${ }^{\text {del }}$ allele or no KIR2DS4 allele $(\mathrm{HR}=7.9 ; p=0.016)$. In the MUD group, HSCT from a KIR2DS4 ${ }^{\text {full }}$ donor was associated with a higher risk for GVHD (HR $=8.2 ; p=0.012)$ and non-relapse mortality (NRM) than from a donor with KIR2DS4 $4^{\text {del }}$ allele or no KIR2DS4 allele [101]. Another study in 75 Chinese patients who underwent T-cell deplete MUD HSCT showed significantly higher risk of acute GVHD (RR 9.0, $p=0.01$ ) in patients whose donors were homozygous for KIR2DS 4 full allele [102]. It remains to be explored if these effects are restricted to particular racial and ethnic groups, as KIR diversity varies dramatically among different populations.

\section{Role of NK cells in cord blood transplant}

Umbilical cord blood transplant (CBT) generates a multifaceted NK cell alloreactive environment, especially in patients who receive double unit CBT, where three-way interactions between two CB units and the host make it even more complex to fully comprehend the role of NK cells than in other types of HSCT. This has been investigated in a handful of studies that generated controversial findings. The beneficial effect of KIR ligand mismatch in CBT was demonstrated in 
only one study in patients with acute leukemia $(n=218)$, in which the authors reported a lower risk of relapse and improved OS in the KIR ligand-mismatched group. The majority of patients in this study received in vivo T-cell depletion (82\%) and myeloablative conditioning (83\%) and all patients received a single CB unit [103]. Subsequent studies in heterogeneous populations that included either single or double unit CBT, with or without lymphodepletion and a blend of conditioning regimens displayed inconsistent outcomes [104-107]. Three of these studies [105-107] showed no impact of KIR ligand mismatch on outcomes after CBT, while one study [104] revealed rather unfavorable outcomes in patients receiving KIR ligand-mismatched RIC-CBT, with a higher risk of acute GVHD and NRM and lower OS.

More recently, a study by our group assessed whether specific combinations of donor-recipient KIR-HLA genotypes could improve outcomes after CBT [108]. This study included 110 patients with myeloid or lymphoid malignancies who received predominantly double unit (95\%) CBT following myeloablative (72\%) or RIC regimens. HLA$\mathrm{C} 1 / \mathrm{x}$ patients had significantly better outcomes (lower relapse and superior survival) than homozygous HLA-C2 patients, related to the observation that the HLA-C1-specific KIR2DL2/L3/S2-expressing NK cells appeared significantly earlier and in greater numbers after CBT than the HLA C2-specific KIR2DL1/S1-expressing NK cells. Among HLA $\mathrm{C} 1 / \mathrm{x}$ patients, those who received a graft with a combined HLA-C1-KIR2DL2/L3/S2 genotype (where donor NK cells were licensed for KIR2DL2 or 2DL3 and expressed activating KIR2DS2) had a significantly lower risk of relapse and improved OS than those with CB grafts lacking KIR2DS2 or HLA-C1 (i.e., where donor NK cells were either not licensed or the activating KIR2DS2 gene was absent). Similarly, HLA-C2/C2 patients had a lower risk of relapse and improved survival if they received a graft with the combined HLA-C2-KIR2DL1/S1 genotype (i.e., where CB NK cells were licensed for KIR2DL1 and the activating KIR2DS1 gene was present) [108]. Based on these findings, we initiated a clinical trial of personalized CBT in patients with hematological malignancies, where we select a CB unit with the best probability of eliciting NK alloreactive responses. For instance, for $\mathrm{C} 1 / \mathrm{x}$ patients, we select at least one $\mathrm{CB}$ unit that is positive for licensed KIR2DL2/L3 and the activating KIR gene KIR2DS2. For C2/C2 patients, we infuse activated mature CB NK cells expressing the $\mathrm{C} 2$-specific NK receptor KIR2DL1 (expanded from the dominant CB unit determined at the time of engraftment by chimerism analysis) between 1 and 3 months post-transplant to reduce the risk of relapse [NCT02727803]. In addition, given the unique advantages of CB-derived NK cells (reviewed in [109]), we are also conducting other clinical trials where ex vivo expanded CB NK cells are infused along with high-dose chemotherapy in the setting of HSCT in patients with lymphoma
[NCT03019640], multiple myeloma [NCT01729091] or leukemia [NCT01619761].

\section{Allogeneic NK cells as a stand-alone therapy}

The findings generated from the studies of KIR ligand-mismatched haploidentical HCT suggested safety and potential efficacy of using allogeneic NK cells as stand-alone therapy. This was first explored in the non-transplant setting by Miller et al. [110] in 43 patients with solid tumors, Hodgkin disease and relapsed/refractory AML who were given infusions of haploidentical NK cells followed by exogenous IL-2. All patients received one of three lymphodepleting preparative regimens to prevent rejection of donor cells, including (a) low-dose cyclophosphamide $\left(750 \mathrm{mg} / \mathrm{m}^{2}\right)$ and methylprednisolone, (b) fludarabine $\left(25 \mathrm{mg} / \mathrm{m}^{2}\right.$ for 5 days $)$ or (c) high-dose cyclophosphamide $(60 \mathrm{mg} / \mathrm{kg}$ for 1 or 2 doses) and fludarabine ( $25 \mathrm{mg} / \mathrm{m}^{2}$ for 5 days) ("Hi-Cy/Flu"). Of these, the most potent lymphodepleting $\mathrm{Hi}-\mathrm{Cy} / \mathrm{Flu}$ regimen induced massive T-cell lymphopenia resulting in high endogenous concentrations of IL-15 and the best in vivo expansion of NK cells. No patient developed GVHD and 5 of the 19 AML patients attained CR, with higher responses seen in those with a KIR ligand-mismatched donor [110]. In a subsequent study [111], the authors incorporated a recombinant IL-2 diphtheria fusion protein (IL2DT) into the $\mathrm{Hi}-\mathrm{Cy} / \mathrm{Flu}$ conditioning regimen $(n=15)$ to deplete Tregs and noted even higher expansion of NK cells, which translated into higher rates of CR at day 28 ( 53 vs. $21 \% ; p=0.02$ ) and PFS at 6 months (33 vs. 5\%; $p<0.01$ ) compared to those who did not receive IL2DT $(n=42)$ [111].

\section{Future directions: next generation engineered NK cells for immunotherapy of cancer}

Allogeneic NK cells have proven to be safe with modest efficacy in clinical trials as detailed above. However, there are still some limitations that need to be overcome for NK cellular therapy to have a larger clinical impact. Some of these obstacles include limited in vivo persistence, restricted homing to tumor sites, hampered function due to the immunosuppressive tumor microenvironment and lack of antigen specificity. The field of genetic engineering has seen tremendous advances in the past few years and has proven to be a powerful approach to improve the efficacy of immune effector cells for adoptive therapy. The most notable advances were seen with T-cell therapy, and have led to the Food and Drug Administration (FDA) approval of CD19redirected chimeric antigen receptor (CAR) engineered $\mathrm{T}$ cells for relapsed B-ALL in children and young adults [112] 
and for patients with relapsed NHL [113]. These advances have also applied to the field of NK cellular therapy where CAR engineering is being explored in multiple preclinical studies (reviewed in [114-116]). Our group is leading the first in-human clinical trial to test the safety and efficacy of off-the-shelf CB-NK cells engineered to express a CAR against CD19, ectopically produce IL-15 to support NK cell proliferation and persistence in vivo, and express a suicide gene, inducible caspase 9 , to address any potential safety concerns for the treatment of refractory lymphoid malignancies [NCT03056339]. Genetic engineering can be employed to enhance the effectiveness of adoptively transferred NK cells by increasing their in vivo persistence and cytotoxicity, improve their trafficking and homing to tumor sites and enhance their ability to circumvent the immunosuppressive tumor microenvironment [reviewed in [115, 116]. In addition to CAR engineering, other strategies, including bi-specific killer cell engagers (BiKEs) and tri-specific killer cell engagers (TriKEs) are also being employed to enhance the efficacy of NK cellular therapy (reviewed in [117-119]).

\section{Conclusion}

The field of NK cell immunotherapy has advanced remarkably over the last decade. Although initial studies with autologous NK cells were discouraging, the use of allogeneic NK cells has resulted in favorable outcomes both in the transplant and non-transplant settings. Our increasing understanding of the biology of NK cells along with the advancements in the field of ex vivo manipulation and genetic engineering is laying the foundation for readily available universal, yet customizable, NK cells for the adoptive immunotherapy of cancer.

\section{Compliance with ethical standards}

Conflict of interest The authors have no conflict of interest with the information provided in this article.

\section{References}

1. Mehta RS, Rezvani K. Immune reconstitution post allogeneic transplant and the impact of immune recovery on the risk of infection. Virulence. 2016;7(8):901-16.

2. Ruggeri L, Capanni M, Aversa F, et al. Effectiveness of donor natural killer cell alloreactivity in mismatched hematopoietic transplants. Science. 2002;295:2097-100.

3. Asai O, Longo DL, Tian ZG, Hornung RL, Taub DD, Ruscetti FW, et al. Suppression of graft-versus-host disease and amplification of graft-versus-tumor effects by activated natural killer cells after allogeneic bone marrow transplant. J Clin Investig. 1998;101(9):1835-42.
4. Ruggeri L, Mancusi A, Burchielli E, Capanni M, Carotti A, Aloisi T, et al. NK cell alloreactivity and allogeneic hematopoietic stem cell transplant. Blood Cells Mol Dis. 2008;40(1):84-90.

5. Ruggeri L, Mancusi A, Burchielli E, Aversa F, Martelli MF, Velardi A. Natural killer cell alloreactivity in allogeneic hematopoietic transplant. Curr Opin Oncol. 2007;19(2):142-7.

6. Suck G, Branch DR, Keating A. Irradiated KHYG-1 retains cytotoxicity: potential for adoptive immunotherapy with a natural killer cell line. Int J Radiat Biol. 2006;82(5):355-61.

7. Gong JH, Maki G, Klingemann HG. Characterization of a human cell line (NK-92) with phenotypical and functional characteristics of activated natural killer cells. Leukemia. 1994;8(4):652-8.

8. Bock AM, Knorr D, Kaufman DS. Development, expansion, and in vivo monitoring of human NK cells from human embryonic stem cells (hESCs) and induced pluripotent stem cells (iPSCs). J Vis Exp. 2013;74:e50337.

9. Kruse V, Hamann C, Monecke S, Cyganek L, Elsner L, Hubscher $\mathrm{D}$, et al. Human induced pluripotent stem cells are targets for allogeneic and autologous natural killer (NK) cells and killing is partly mediated by the activating NK receptor DNAM-1. PLoS One. 2015;10(5):e0125544.

10. De Maria A, Bozzano F, Cantoni C, Moretta L. Revisiting human natural killer cell subset function revealed cytolytic CD56(dim) $\mathrm{CD}^{1} 6^{+} \mathrm{NK}$ cells as rapid producers of abundant INF-gamma on activation. Proc Natl Acad Sci USA. 2011;108:728-32.

11. Ljunggren $\mathrm{H}$, Karre K. In search of the 'missing self': MHC molecules and NK cell recognition. Inflamm Allergy Drug Targets. 2014;13(2):128-33.

12. Vidal S, Khakoo S, Biron C. Natural killer cell responses during viral infections: flexibility and conditioning of innate immunity by experience. Curr Opin Virol. 2011;1(6):497-512.

13. Kiessling R, Petranyi G, Karre K, Jondal M, Tracey D, Wigzell H. Killer cells: a functional comparison between natural, immune T-cell and antibody-dependent in vitro systems. J Exp Med. 1976;143(4):772-80.

14. IPD-KIR. The Immuno Polymorphism Database (IPD). https:// www.ebi.ac.uk/ipd/kir/introduction.html; 2003.

15. Foley BA, De Santis D, Van Beelen E, Lathbury LJ, Christiansen FT, Witt CS. The reactivity of Bw4 + HLA-B and HLA-A alleles with KIR3DL1: implications for patient and donor suitability for haploidentical stem cell transplants. Blood. 2008;112(2):435-43.

16. Winter CC, Gumperz JE, Parham P, Long EO, Wagtmann N. Direct binding and functional transfer of NK cell inhibitory receptors reveal novel patterns of HLA-C allotype recognition. J Immunol. 1998;161(2):571-7.

17. Kim S, Poursine-Laurent J, Truscott S, Lybarger L, Song Y, Yang $\mathrm{L}$, et al. Licensing of natural killer cells by host major incompatibility complex class I molecules. Nature. 2005;436:709-13.

18. Anfossi N, Andre P, Guia S, Falk C, Roetynck S, Stewart C, et al. Human NK cell education by inhibitory receptors for MHC class I. Immunity. 2006;25:331-42.

19. Cosman D, Mullberg J, Sutherland C, Chin W, Armitage R, Fanslow W, et al. ULBPs, novel MHC class I-related molecules, bind to CMV glycoprotein UL16 and stimulate NK cytotoxicity through the NKG2D receptor. Immunity. 2001;14:123-33.

20. Lanier L. NK cell recognition. Annu Rev Immunol. 2005;23:225-74.

21. Pende D, Parolini S, Pessino A, Sivori S, Augugliaro R, Morelli $\mathrm{L}$, et al. Identification and molecular characterization of NKp30. A novel triggering receptor involved in natural cytotoxicity mediated by human natural killer cells. J Exp Med. 1999;190:1505-16.

22. Baychelier F, Sennepin A, Ermonval M, Dorgham K, Debre P, Vieillard V. Identification of a cellular ligand for the natural cytotoxicity receptor NKp44. Blood. 2013;122:2935-42. 
23. Vitale M, Bottino C, Sivori S, Sanseverino L, Castriconi R, Marcenaro E, et al. NKp44, a novel triggering surface molecule specifically expressed by activated natural killer cells, is involved in non-major histocompatibility complex-restricted tumor cell lysis. J Exp Med. 1998;187:2065-72.

24. Mandelboim O, Lieberman N, Lev M, Paul L, Arnon T, Bushkin Y, et al. Recognition of haemagglutinins on virus-infected cells by NKp46 activates lysis by human NK cells. Nature. 2001;409:1055-60.

25. Sivori S, Vitale M, Morelli L, Sanseverino L, Augugliaro $\mathrm{R}$, Bottino C, et al. p46, a novel natural killer cell-specific surface molecule that mediates cell activation. J Exp Med. 1997;1997:1129-36.

26. Claus M, Meinke S, Bhat R, Watzl C. Regulation of NK cell activity by $2 \mathrm{~B} 4$, NTB-A and CRACC. Front Biosci. 2008;13:956-65.

27. de Andrade L, Smyth M, Martinet L. DNAM-1 control of natural killer cells functions through nectin and nectin-like proteins. Immunol Cell Biol. 2013;17:95.

28. Blokhuis JH, Hilton HG, Guethlein LA, Norman PJ, Nemat-Gorgani N, Nakimuli A, et al. KIR2DS5 allotypes that recognize the C2 epitope of HLA-C are common among Africans and absent from Europeans. Immun Inflamm Dis. 2017;5(4):461-8.

29. David G, Djaoud Z, Willem C, Legrand N, Rettman P, Gagne $\mathrm{K}$, et al. Large spectrum of HLA-C recognition by killer Iglike receptor (KIR)2DL2 and KIR2DL3 and restricted C1 SPECIFICITY of KIR2DS2: dominant impact of KIR2DL2/ KIR2DS2 on KIR2D NK cell repertoire formation. J Immunol. 2013;191(9):4778-88.

30. Pittari G, Liu XR, Selvakumar A, Zhao Z, Merino E, Huse $\mathrm{M}$, et al. NK cell tolerance of self-specific activating receptor KIR2DS1 in individuals with cognate HLA-C2 ligand. J Immunol. 2013;190(9):4650-60.

31. Chewning JH, Gudme CN, Hsu KC, Selvakumar A, Dupont B. KIR2DS1-positive NK cells mediate alloresponse against the $\mathrm{C} 2$ HLA-KIR ligand group in vitro. J Immunol. 2007;179(2):854-68.

32. Liu J, Xiao Z, Ko HL, Shen M, Ren EC. Activating killer cell immunoglobulin-like receptor 2DS2 binds to HLA-A*11. Proc Natl Acad Sci USA. 2014;111(7):2662-7.

33. Thiruchelvam-Kyle L, Hoelsbrekken SE, Saether PC, Bjornsen EG, Pende D, Fossum S, et al. The activating human NK cell receptor KIR2DS2 recognizes a beta2-microglobulin-independent ligand on cancer cells. J Immunol. 2017;198(7):2556-67.

34. Eleme K, Taner SB, Onfelt B, Collinson LM, McCann FE, Chalupny NJ, et al. Cell surface organization of stress-inducible proteins ULBP and MICA that stimulate human NK cells and T cells via NKG2D. J Exp Med. 2004;199(7):1005-10.

35. Harel-Bellan A, Quillet A, Marchiol C, DeMars R, Tursz T, Fradelizi D. Natural killer susceptibility of human cells may be regulated by genes in the HLA region on chromosome 6. Proc Natl Acad Sci USA. 1986;83(15):5688-92.

36. Ljunggren $\mathrm{HG}$, Karre K. In search of the 'missing self': MHC molecules and NK cell recognition. Immunol Today. 1990;11(7):237-44.

37. Herberman R, Nunn M, Lavrin D. Natural cytotoxic reactivity of mouse lymphoid cells against syngeneic acid allogeneic tumors. I. Distribution of reactivity and specificity. Int J Cancer. 1975;16(2):216-29.

38. Karre K, Ljunggren H, Piontek G, Kiessling R. Selective rejection of H-2-deficient lymphoma variants suggests alternative immune defense strategy. Nature. 1986;319:675-8.

39. Wu J, Song Y, Bakker A, Bauer S, Spies T, Lanier L, et al. An activating immunoreceptor complex formed by NKG2D and DAP10. Science. 1999;285:730-2.

40. Garrity D, Call M, Feng J, Wucherpfennig K. The activating NKG2D receptor assembles in the membrane with two signaling dimers into a hexameric structure. Proc Natl Acad Sci USA. 2005;102:7641-6.

41. Moretta A, Bottino C, Vitale M, Pende D, Cantoni C, Mingari M, et al. Activating receptors and coreceptors involved in human natural killer cell-mediated cytolysis. Annu Rev Immunol. 2001;19:197-223.

42. Farag S, Caligiuri M. Human natural killer cell development and biology. Blood Rev. 2006;20:123-37.

43. Romee R, Foley B, Miller J, et al. NK cell CD16 surface expression and function is regulated by a disintegrin and metalloprotease-17 (ADAM17). Blood. 2013;121(18):3599-608.

44. Robinson N, Benyunes M, Thompson J, York A, Petersdorf S, Press $\mathrm{O}$, et al. Intrleukin-2 after autologous stem cell transplant for hematologic malignancy: a phase I/II study. Bone Marrow Transplant. 1997;19(5):435-42.

45. Blaise D, Attal M, Pico J, Reiffers J, Stoppa A, Bellanger C, et al. The use of sequential high dose recombinant interleukin 2 regimen after autologous bone marrow transplant does not improve the disease free survival of patients with acute leukemia transplanted in first complete remission. Leuk Lymphoma. 1997;25(5-6):469-78.

46. Meropol N, Porter M, Blumenson L, Lindemann M, Perez R, Vaickus L, et al. Daily subcutaneous injection of low-dose interleukin 2 expands natural killer cells in vivo without significant toxicity. Clin Cancer Res. 1996;2(4):669-77.

47. Caligiuri M, Murray C, Soiffer R, Klumpp T, Seiden M, Cochran K, et al. Extended continuous infusion low-dose recombinant interleukin-2 in advanced cancer: prolonged immunomodulation without significant toxicity. J Clin Oncol. 1991;9(12):2110-9.

48. Soiffer R, Murray C, Cochran K, Cameron C, Wang E, Schow $\mathrm{P}$, et al. Clinical and immunologic effects of prolonged infusion of low-dose recombinant interleukin-2 after autologous and T-cell-depleted allogeneic bone marrow transplant. Blood. 1992;79(2):517-26.

49. Miller J, Tessmer-Tuck J, Pierson B, Weisdorf D, McGlave P, Blazar B, et al. Low dose subcutaneous interleukin-2 after autologous transplant generates sustained in vivo natural killer cell activity. Biol Blood Marrow Transplant. 1997;3(1):34-44.

50. Weisdorf D, Anderson P, Blazar B, Uckun F, Kersey J, Ramsay N. Interleukin 2 immediately after autologous bone marrow transplant for acute lymphoblastic leukemia-a phase I study. Transplant. 1993;55(1):61-6.

51. Rosenburg S, Lotze M, Muul L, Leitman S, Chang A, Ettinghausen $\mathrm{S}$, et al. Observations on the systemic administration of autologous lymphokine-activated killer cells and recombinant interleukin-2 to patients with metastatic cancer. N Engl J Med. 1985;313:1485-92.

52. Rosenburg S, Lotze M, Muul L, Chang A, Avis F, Leitman S, et al. A progress report on the treatment of 157 patients with advanced cancer using lymphokine-activated killer cells and interleukin-2 or high-dose interleukin-2 alone. N Engl J Med. 1987;316(15):889-97.

53. Benyunes M, Higuchi C, York A, Lindgren C, Thompson J, Buckner $\mathrm{C}$, et al. Immunotherapy with interleukin 2 with or without lymphokine-activated killer cells after autologous bone marrow transplantation for malignant lymphoma: a feasibility trial. Bone Marrow Transplant. 1995;16(2):283-8.

54. Benyunes M, Massumoto C, York A, Higuchi C, Buckner C, Thompson J, et al. Interleukin-2 with or without lymphokineactivated killer cells as consolidative immunotherapy after bone marrow transplant for acute myelogenous leukemia. Bone Marrow Transplant. 1993;12(2):159-63.

55. Lister J, Rybka W, Donnenberg A, de Magalhaes-Silverman M, Pincus S, Bloom E, et al. Autologous peripheral blood stem cell transplant and adoptive immunotherapy with activated 
natural killer cells in the immediate posttransplant period. Clin Cancer Res. 1995;1(6):607-14.

56. de Magalhaes-Silverman M, Donnenberg A, Lembersky B, Elder E, Lister J, Rybka W, et al. Posttransplant adoptive immunotherapy with activated natural killer cells in patients with metastatic breast cancer. J Immunother. 2000;23(1):154-60.

57. Burns L, Weisdorf D, DeFor T, Vesole D, Repka T, Blazar B, et al. IL-2-based immunotherapy after autologous transplant for lymphoma and breast cancer induces immune activation and cytokine release: a phase I/II trial. Bone Marrow Transplant. 2003;32(2):177-86.

58. Knorr D, Bachanova V, Verneris M, Miller J. Clinical utility of natural killer cells in cancer therapy and transplant. Semin Immunol. 2014;26:161-72.

59. Trowsdale J. Genetic and functional relationships between MHC and NK receptor genes. Immunity. 2001;15(3):363-74.

60. Shilling HG, Young N, Guethlein LA, Cheng NW, Gardiner CM, Tyan D, et al. Genetic control of human NK cell repertoire. J Immunol. 2002;169(1):239-47.

61. Ruggeri L, Mancusi A, Capanni M, Urbani E, Carotti A, Aloisi $\mathrm{T}$, et al. Donor natural killer cell allorecognition of missing self in haploidentical hematopoietic transplant for acute myeloid leukemia: challenging its predictive value. Blood. 2007;110(1):433-40.

62. Ciurea S, Mulanovich V, Saliba R, Bayraktar U, Jiang Y, Bassett $\mathrm{R}$, et al. Improved early outcomes using a $\mathrm{T}$ cell replete graft compared with $\mathrm{T}$ cell depleted haploidentical hematopoietic stem cell transplant. Biol Blood Marrow Transplant. 2012;18(12):1835-44.

63. Handgretinger R, Klingebiel T, Lang P, Schumm M, Neu S, Geiselhart A, et al. Megadose transplant of purified peripheral blood CD34(+) progenitor cells from HLA-mismatched parental donors in children. Bone Marrow Transplant. 2001;27(8):777-83.

64. Powles RL, Morgenstern GR, Kay HE, McElwain TJ, Clink HM, Dady PJ, et al. Mismatched family donors for bonemarrow transplant as treatment for acute leukaemia. Lancet. 1983;1(8325):612-5.

65. Luznik L, O’Donnell PV, Fuchs EJ. Post-transplant cyclophosphamide for tolerance induction in HLA-haploidentical bone marrow transplant. Semin Oncol. 2012;39(6):683-93.

66. Passweg J, Baldomero H, Bader P, et al. Use of haploidentical stem cell transplant continues to increase: the 2015 European Society for Blood and Marrow Transplant activity survey report. Bone Marrow Transplant. 2017;52:811-7.

67. Apperly J, Niederwieser D, Huang X-J, et al. Haploidentical hematopoietic stem cell transplant: a global overview comparing Asia, the European Union and the United States. Biol Blood Marrow Transplant. 2016;22(1):23-6.

68. Russo A, Oliveira G, Vago L, et al. NK cell dynamics after haplo-HSCT with post-transplant cyclophosphamide. Blood. 2018;131:247-62.

69. Wanquet A, Bramanti S, Harbi S, Furst S, Legrand F, Faucher $\mathrm{C}$, et al. KIR-ligand mismatch in donor vs recipient direction provides better graft-versus-tumor effect in patients with hematological malignancies undergoing allogeneic T-replete haploidentical transplant followed by post-transplant cyclophosphamide. Biol Blood Marrow Transplant. 2017. https://doi.org/10.1016/j. bbmt.2017.11.042.

70. Retiere C, Willem C, Legrand N, Guillaume T, Gagne K, Peterlin P, et al. NK-cell alloreactivity is associated with acute Gvhd and decreased relapse incidence after T-replete haplo-identical allotransplant with high-dose post-transplant cyclophosphamide. Blood. 2017;130:3262.

71. Ciurea S, Schafer J, Bassett R, Denman C, Cao K, Willis D, et al. Phase 1 clinical trial using mbIL21 ex vivo-expanded donor-derived NK cells after haploidentical transplant. Blood. 2017;130(16):1857-68.

72. Hsu K, Keever-Taylor C, Wilton A, et al. Improved outcome in HLA-identical sibling hematopoietic stem-cell transplant for acute myelogenous leukemia predicted by KIR and HLA genotypes. Blood. 2005;105(12):4878-84.

73. Beelen D, Ottinger H, Ferencik S, et al. Genotypic inhibitory killer immunoglobulin-like receptor ligand incompatibility enhances the long-term antileukemic effect of unmodified allogeneic hematopoietic stem cell transplant in patients with myeloid leukemias. Blood. 2005;105(6):2594-600.

74. Verheyden S, Schots R, Duquet W, Demanet C. A defined donor activating natural killer cell receptor genotype protects against leukemic relapse after related HLA-identical hematopoietic stem cell transplant. Leukemia. 2005;19(8):1446-51.

75. Chen C, Busson M, Rocha V, et al. Activating KIR genes are associated with CMV reactivation and survival after nonT-cell depleted HLA-identical sibling bone marrow transplant for malignant disorders. Bone Marrow Transplant. 2006;38(6):437-44.

76. Sun J, Dagis A, Gaidulis L, et al. Detrimental effect of natural killer cell alloreactivity in T-replete hematopoietic cell transplant (HCT) for leukemia patients. Biol Blood Marrow Transplant. 2007;13(2):197-205.

77. Davies S, Ruggieri L, DeFor T, et al. Evaluation of KIR ligand incompatibility in mismatched unrelated donor hematopoietic transplants. Killer immunoglobulin-like receptor. Blood. 2002;100(10):3825-7.

78. Giebel S, Locatelli F, Lamparelli T, et al. Survival Advantage with KIR ligand incompatibility in hematopoietic stem cell transplant using unrelated donors. Blood. 2003;102(3):814-9.

79. Bornhauser M, Schwerdtfeger R, Martin H, Frank K, Theuser C, Ehninger G. Role of KIR ligand incompatibility in hematopoietic stem cell transplant using unrelated donors. Blood. 2004;103(7):2860-1.

80. Schaffer M, Malmberg K, Ringden O, Ljunggren H, Remberger M. Increased infection-related mortality in KIR-ligand-mismatched unrelated allogeneic hematopoietic stem-cell transplant. Transplant. 2004;78(7):1081-5.

81. Farag S, Bacigalupo A, Eapen M, et al. The effect of KIR ligand incompatibility on the outcome of unrelated donor transplant: a report from the center for international blood and marrow transplant research, the European blood and marrow transplant registry and the Dutch registry. Biol Blood Marrow Transplant. 2006;12(8):876-84.

82. Kroger N, Binder T, Zabelina T, et al. Low number of donor activating killer immunoglobulin-like receptors (KIR) genes but not KIR-ligand mismatch prevents relapse and improves disease free survival in leukemia patients after in vivo T-cell depleted unrelated stem cell transplant. Transplant. 2006;82(8):1024-30.

83. Miller J, Cooley S, Parham P, et al. Missing KIR ligands are associated with less relapse and increased graft-versus-host disease (GVHD) following unrelated donor allogeneic HCT. Blood. 2007;109(11):5058-61.

84. Bishara A, De Santis D, Witt CC, Brautbar C, Christiansen FT, Or R, et al. The beneficial role of inhibitory KIR genes of HLA class I NK epitopes in haploidentically mismatched stem cell allografts may be masked by residual donor-alloreactive $\mathrm{T}$ cells causing GVHD. Tissue Antigens. 2004;63(3):204-11.

85. Lowe EJ, Turner V, Handgretinger R, Horwitz EM, Benaim E, Hale GA, et al. T-cell alloreactivity dominates natural killer cell alloreactivity in minimally T-cell-depleted HLA-nonidentical paediatric bone marrow transplant. Br J Haematol. 2003; 123(2):323-6.

86. Shen M, Linn YC, Ren EC. KIR-HLA profiling shows presence of higher frequencies of strong inhibitory KIR-ligands 
among prognostically poor risk AML patients. Immunogenetics. 2016;68(2):133-44.

87. Marra J, Greene J, Hwang J, Du J, Damon L, Martin T, et al. KIR and HLA genotypes predictive of low-affinity interactions are associated with lower relapse in autologous hematopoietic cell transplant for acute myeloid leukemia. J Immunol. 2015; 194(9):4222-30.

88. Yawata M, Yawata N, Draghi M, Little AM, Partheniou F, Parham P. Roles for HLA and KIR polymorphisms in natural killer cell repertoire selection and modulation of effector function. $\mathrm{J}$ Exp Med. 2006;203(3):633-45.

89. Draghi M, Yawata N, Gleimer M, Yawata M, Valiante NM, Parham P. Single-cell analysis of the human NK cell response to missing self and its inhibition by HLA class I. Blood. 2005;105(5):2028-35.

90. Boudreau JE, Giglio F, Gooley TA, Stevenson PA, Le Luduec JB, Shaffer BC, et al. KIR3DL1/HL A-B subtypes govern acute myelogenous leukemia relapse after hematopoietic cell transplant. J Clin Oncol. 2017;35(20):2268-78.

91. Pyo CW, Guethlein LA, Vu Q, Wang R, Abi-Rached L, Norman PJ, et al. Different patterns of evolution in the centromeric and telomeric regions of group A and B haplotypes of the human killer cell Ig-like receptor locus. PLoS One. 2010;5(12):e15115.

92. Cooley S, Trachtenburg E, Bergemann T, et al. Donors with group B KIR haplotypes improve relapse-free survival after unrelated hematopoietic cell transplant for acute myelogenous leukemia. Blood. 2009;113(3):726-32.

93. Cooley S, Weisdorf DJ, Guethlein LA, Klein JP, Wang T, Le CT, et al. Donor selection for natural killer cell receptor genes leads to superior survival after unrelated transplant for acute myelogenous leukemia. Blood. 2010;116(14):2411-9.

94. Cooley S, Weisdorf DJ, Guethlein LA, Klein JP, Wang T, Marsh $\mathrm{SG}$, et al. Donor killer cell Ig-like receptor B haplotypes, recipient HLA-C1, and HLA-C mismatch enhance the clinical benefit of unrelated transplant for acute myelogenous leukemia. J Immunol. 2014;192(10):4592-600.

95. Neuchel C, Furst D, Niederwieser D, Bunjes D, Tsamadou C, Wulf G, et al. Impact of donor activating KIR genes on HSCT outcome in C1-ligand negative myeloid disease patients transplanted with unrelated donors - a retrospective study. PLoS One. 2017;12(1):e0169512.

96. Venstrom JM, Dupont B, Hsu KC, Pittari G, Gooley TA, Chewning JH, et al. Donor activating KIR2DS1 in leukemia. N Engl J Med. 2014;371(21):2042.

97. Venstrom JM, Pittari G, Gooley TA, Chewning JH, Spellman $\mathrm{S}$, Haagenson M, et al. HLA-C-dependent prevention of leukemia relapse by donor activating KIR2DS1. N Engl J Med. 2012;367(9):805-16.

98. Gonzalez-Galarza FF, Takeshita LY, Santos EJ, Kempson F, Maia MH, da Silva AL, et al. Allele frequency net 2015 update: new features for HLA epitopes, KIR and disease and HLA adverse drug reaction associations. Nucleic Acids Res. 2015;43(Database issue):D784-8.

99. Middleton D, Gonzalez A, Gilmore PM. Studies on the expression of the deleted KIR2DS4*003 gene product and distribution of KIR2DS4 deleted and nondeleted versions in different populations. Hum Immunol. 2007;68(2):128-34.

100. Maxwell LD, Williams F, Gilmore P, Meenagh A, Middleton D. Investigation of killer cell immunoglobulin-like receptor gene diversity: II. KIR2DS4. Hum Immunol. 2004;65(6):613-21.

101. Burek Kamenaric M, Stingl Jankovic K, Grubic Z, Serventi Seiwerth R, Maskalan M, Nemet D, et al. The impact of KIR2DS4 gene on clinical outcome after hematopoietic stem cell transplant. Hum Immunol. 2017;78(2):95-102.
102. Bao XJ, Hou LH, Sun AN, Qiu QC, Yuan XN, Chen MH, et al. The impact of KIR2DS4 alleles and the expression of KIR in the development of acute GVHD after unrelated allogeneic hematopoietic SCT. Bone Marrow Transplant. 2010;45(9):1435-41.

103. Willemze R, Rodrigues CA, Labopin M, Sanz G, Michel G, Socie G, et al. KIR-ligand incompatibility in the graft-versushost direction improves outcomes after umbilical cord blood transplant for acute leukemia. Leukemia. 2009;23(3):492-500.

104. Brunstein C, Wagner J, Barker J, et al. Negative effect of KIR alloreactivity in recipients of umbilical cord blood transplant depends on transplant conditioning intensity. Blood. 2009;113(22):5628-34.

105. Tanaka J, Morishima Y, Takahashi Y, et al. Effects of KIR ligand incompatibility on clinical outcomes of umbilical cord blood transplant without ATG for acute leukemia in complete remission. Blood Cancer J. 2013;3:e164.

106. Garfall A, Kim H, Sun L, et al. KIR ligand incompatibility is not associated with relapse reduction after double umbilical cord blood transplant. Bone Marrow Transplant. 2013;48(7):1000-2.

107. Rocha V, Ruggeri A, Spellman S, et al. Eurocord, Netcord, and the Center for International Blood and Marrow Transplant Research. Killer cell immunoglobulin-like receptor-ligand matching and outcomes after unrelated cord blood transplant in acute myeloid leukemia. Biol Blood Marrow Transplant. 2016;22(7):1284-9.

108. Sekine T, Marin D, Cao K, Cao K, Li L, Mehta P, et al. Specific combinations of donor and recipient KIR-HLA genotypes predict for large differences in outcome after cord blood transplant. Blood. 2016;128(2):297-312.

109. Mehta RS, Shpall EJ, Rezvani K. Cord blood as a source of natural killer cells. Front Med (Lausanne). 2015;2:93.

110. Miller JS, Soignier Y, Panoskaltsis-Mortari A, McNearney SA, Yun GH, Fautsch SK, et al. Successful adoptive transfer and in vivo expansion of human haploidentical NK cells in patients with cancer. Blood. 2005;105(8):3051-7.

111. Bachanova V, Cooley S, Defor T, Verneris M, Zhang B, McKenna $\mathrm{D}$, et al. Clearance of acute myeloid leukemia by haploidentical natural killer cells is improved using IL-2 diphtheria toxin fusion protein. Blood. 2014;123(25):3855-63.

112. FDA. FDA approval brings first gene therapy to the United States. https://www.fda.gov/NewsEvents/Newsroom/PressAnnou ncements/ucm574058.htm. Accessed 30 Aug 2017.

113. FDA. FDA approves CAR-T cell therapy to treat adults with certain types of large B-cell lymphoma. https://www.fda.gov/ NewsEvents/Newsroom/PressAnnouncements/ucm581216.htm. Accessed 18 Oct 2017.

114. Rezvani K, Rouce R, Liu E, Shpall E. Engineering natural killer cells for cancer immunotherapy. Mol Ther. 2017;25(8):1769-81.

115. Carlsten M, Childs RW. Genetic manipulation of NK cells for cancer immunotherapy: techniques and clinical implications. Front Immunol. 2015;6:266.

116. Guillerey C, Huntington ND, Smyth MJ. Targeting natural killer cells in cancer immunotherapy. Nat Immunol. 2016;17(9):1025-36.

117. Davis ZB, Vallera DA, Miller JS, Felices M. Natural killer cells unleashed: checkpoint receptor blockade and BiKE/TriKE utilization in NK-mediated anti-tumor immunotherapy. Semin Immunol. 2017;31:64-75.

118. Felices M, Lenvik TR, Davis ZB, Miller JS, Vallera DA. Generation of BiKEs and TriKEs to improve NK cell-mediated targeting of tumor cells. Methods Mol Biol. 2016;1441:333-46.

119. Tay SS, Carol H, Biro M. TriKEs and BiKEs join CARs on the cancer immunotherapy highway. Hum Vaccin Immunother. 2016;12(11):2790-6. 